\title{
Apuntes
}

\section{Faros de Andalucía. Sedes web}

\section{Susana Limón Rodriguez}

\section{Sedes web de contenido general}

Faros de España (FEA)

www.iespana.es

En esta sede web encontramos un listado de los principales faros costeros de España, clasificados por provincias, con su denominación y los municipios a los que pertenecen.

\section{Librería Naútica Robinson} www.nauticarobinson.com/

Catálogos de libros sobre diferentes temáticas relacionadas con el mundo náutico y naval se pueden consultar en esta web. Destacamos libros específicos sobre faros, tales como Faros españoles del Mediterráneo, Faro de Mesa Roldán. Apuntes para una historia o Los faros de la costa Atlántica andaluza, entre otros.

\section{Librería Naútica \\ www.libreriadenautica.com/subfamilias/costas_puertos_ faros.html}

Localizamos en esta sede una selección de publicaciones especializadas en faros y puertos de España, con fotografías e historia de los mismos. Todos ellos dentro de la categoría Costas, Puertos, Faros.

Faros de Andalucía

usuarios.lycos.es/librodefaros/andaluci/andallist.htm

Cuenta con una recopilación de todos los faros de Andalucia con enlace a la fotografía de los mismos en detalle, así como su clasificación por cada una de las provincias y una breve descripción de cada uno de ellos, entre otros datos.

\section{Sedes web por provincias}

Los Faros de la provincia de Málaga usuarios.lycos.es/roteng/Faros.htm

Listado general de todos los faros malagueños: Punta Doncella (Estepona), Marbella, Torre del Mar, etc., con ficha individual por cada faro con los siguientes datos de interés: $n^{0}$ nacional, $n^{0}$ internacional, localización, coordenadas, características, elevación, alcance, foto satélite...
Provincia de Málaga: faros, en Wikipedia es.wikipedia.org/wiki/Provincia_de_M\%C3\%A1laga

Encontramos una sección dedicada a los faros marinos situados en la provincia: Faro de Torrox, Faro de Mijas, etc., con ficha y datos identificativos como altura, señales luminosas, alcance teórico y funcionamiento.

Los seis faros del litoral malagueño, en Todo Málaga

Patrimonio Malacitano

webpersonal.uma.es/ JAMOLERO/patrimonio/txt_007.htm

Artículo de Ángel de los Ríos y José Antonio Molero que cuenta con algunas ilustraciones.

Faros de la provincia de Cádiz, en Guía de Cádiz www.guiadecadiz.com/faros.asp

Guía de los catorce faros de la provincia de Cádiz con enlace a una ficha con datos descriptivos del mismo, a través del nombre. También encontramos asociada la localidad a la que pertenecen cada uno de ellos. Los datos de la ficha corresponden a: fotografías disponibles, enclave geográfico, datos generales y descripción.

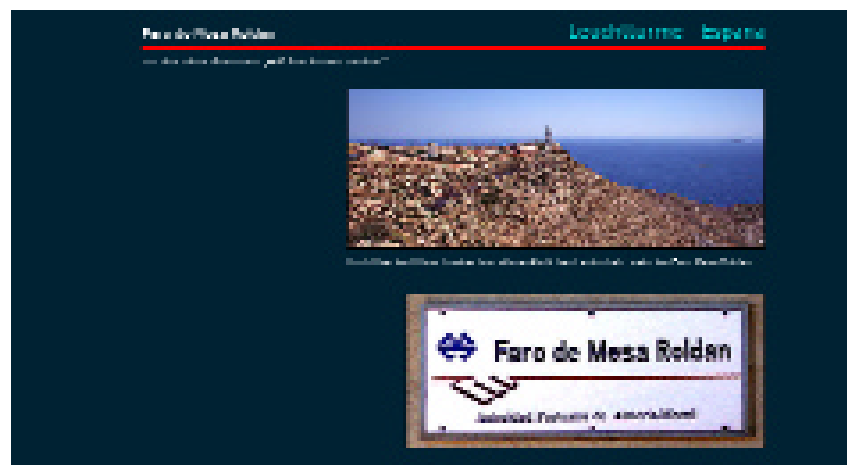

Faros de la Costa de Almería www.todoelmar.com/faros.htm

Listado de los faros de la provincia ubicado en la sede web "Todo el Mar" con el nº de identificación internacional y municipios a los que pertenecen.

Faro de Mesa Roldán home.t-online.de/home/Hans-Guenter.Spitzer/spitzer_web/ album_spanien/roldan_e.html

Página web alemana dedicada a este faro de la provincia de Almeria. 